\title{
Getting Ourselves Together: Data-centered participatory design research \& epistemic burden
}

\author{
Jennifer Pierre \\ University of California, Los Angeles \\ anonymous, USA \\ anonymous
}

\author{
Roderic Crooks \\ University of California, Irvine \\ anonymous, USA \\ anonymous
}

\author{
Morgan E. Currie \\ University of Edinburgh \\ Edinburgh, UK \\ morgan.currie@ed.ac.uk
}

\author{
Britt S. Paris \\ Rutgers University \\ New Brunswick, NJ, USA \\ britt.paris@rutgers.edu
}

\begin{abstract}
Data-centered participatory design research projects-wherein researchers collaborate with community members for the purpose of gathering, generating, or communicating data about the community or their causes-can place epistemic burdens on minoritized or racialized groups, even in projects focused on social justice outcomes. Analysis of epistemic burden encourages researchers to rethink the purpose and value of data in community organizing and activism more generally. This paper describes three varieties of epistemic burden drawn from two case studies based on the authors' previous work with anti-police brutality community organizations. The authors conclude with a discussion of ways to alleviate and avoid these issues through a series of questions about participatory research design. Ultimately, we call for a reorientation of knowledge production away from putative design solutions to community problems and toward a more robust interrogation of the power dynamics of research itself.
\end{abstract}

\section{CCS CONCEPTS}

- Human-centered computing $\rightarrow$ HCI design and evaluation methods.

\section{KEYWORDS}

Critical/Activism/Ethics; Participatory Design

\section{ACM Reference Format:}

Jennifer Pierre, Roderic Crooks, Morgan E. Currie, Britt S. Paris, and Irene V. Pasquetto. 2021. Getting Ourselves Together: Data-centered participatory design research \& epistemic burden. In CHI Conference on Human Factors in Computing Systems (CHI '21), May 8-13, 2021, Yokohama, Japan. ACM, New York, NY, USA, 11 pages. https://doi.org/10.1145/3411764.3445103

\section{INTRODUCTION}

"The function, the very serious function, of racism is distraction. It keeps you from doing your work.

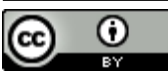

This work is licensed under a Creative Commons Attribution International 4.0 License.

CHI '21, May 8-13, 2021, Yokohama, Japan

(c) 2021 Copyright held by the owner/author(s).

ACM ISBN 978-1-4503-8096-6/21/05.

https://doi.org/10.1145/3411764.3445103

\author{
Irene V. Pasquetto \\ University of Michigan \\ Ann Arbor, Michigan, USA \\ irenevp@umich.edu
}

\begin{abstract}
It keeps you explaining, over and over again, your reason for being. Somebody says you have no language, so you spend twenty years proving that you do. Somebody says your head isn't shaped properly, so you have scientists working on the fact that it is. Somebody says you have no art, so you dredge that up. Somebody says you have no kingdoms and so you dredge that up. None of that is necessary. There will always be one more thing" [36].
\end{abstract}

Recent discussions in the HCI research community have begun to highlight potential challenges and harms in the practice of participatory design (PD) research $[19,26]$. While the method still serves a crucial role in providing space for collaborative community involvement in the research process, and importantly encourages researchers to think intentionally about how to include participants meaningfully in the process, a fresh set of critiques brings to light key areas of improvement for truly meeting those goals. For example, Becker et al. pointed at concerns in PD in the form of pseudo-participation, false consensus, and lack of participants' agency [4]. Others have noted that the proposed solutions to many socio-political problems within $\mathrm{HCI}$ often predictably rely on human-centered design and participatory design, and highlight that a deeper understanding of what PD looks like when working with marginalized communities is necessary [45]. Corbett and Loukissas offer one example of this lack of deeper understanding in their observations that HCI researchers often fail to directly address gentrification because - given their position of privilege - they are more likely to be the "gentrifiers" than the gentrified [16].

This paper adds to this knowledge from a different but related perspective. Building from a self-critique of our own past PD work, we invite researchers to actively engage with the work of identifying and acknowledging the "epistemic burden" hidden within PD practices, in order to adequately prepare and "organize ourselves" before seeking out partnership with community organizations. Other authors before us have critiqued the potentially exploitative nature of these research exchanges, illuminating the pattern of coming into a community; extracting information, experiences, stories, and other data during a participatory design exercise; and then leaving the community without lasting positive impact or appropriate ongoing collaboration or follow-up [26].

A second key concern is the burden this type of research can place on communities. Participants are asked to provide time and 
often resources to take part in collaborative research and are frequently asked to share intimate experiences about their lives; knowledge about their day-to-day practices; information about their families, friends, and community members; cultural and institutional knowledge; and other information that requires energy and effort to gather and provide. Especially if the participatory design research projects are conducted for a short period of time, the direct benefits or purpose of participation for the community are not clear. This becomes particularly important when working with minoritized populations, where the information and experiences requested may center around unearthing and sharing specific traumas or other sensitive details.

Following the work of Muñoz, We use the term minoritized throughout this paper to draw attention to the historical specificity of American racial and sexual hierarchy, to the centrality and persistence of white supremacy, economic precarity, heteronormativity, and misogyny to public life[37]. As work with minoritized communities represents a popular context for participatory research design work, this issue becomes a top priority to resolve. The potential extractive nature of participatory design research also adds irony and complication to a third major issue facing this method, which is the tendency of participatory design research to view communities as bereft. The method sets researchers up to enter into a collaboration with communities to provide a design-based solution to a perceived problem in the community, a problem that often centers around the community lacking something as compared with others. This perception of lack can lead to perpetuating a long-standing issue in research with minoritized communities that paints these communities primarily in a negative light, rather than focusing and building on existing practices, resources, and norms within these communities [49].

As information scholars, we have witnessed these major issues manifest in data-centered participatory design research projects, where researchers collaborate with community members for the purpose of gathering, generating, or communicating data about the community or their causes. In these types of collaborations, community organizers and activists interested in resolving issues facing their communities are asked to work with researchers on a datadriven project intended to empower their communities and gain legitimacy for policy improvement and other aims. This approach can clash with community sentiment that their lived experiences are not appropriately reflected in data points, that empowerment need not involve data, and that data production, use, and dissemination are not suitable avenues for redress of community grievance.

With data-centered participatory research design in particular, asking community groups to produce and use data can entail epistemic burden, a term we use in this paper to refer to multiple related ideas around privileged groups furthering injustice and exploitation through their relationships with oppressed and marginalized community groups. Examples include epistemic exploitation, which Beranstein [7] describes as occurring "when privileged persons compel marginalized persons to produce an education or explanation about the nature of the oppression they face". Another form includes testimonial injustice, where oppressed groups are called to educate privileged groups [22]. A third form includes hermeneutical injustice, where oppressed groups are required to provide "objective" evidence of their oppression [22].
Epistemic burden describes the actual burden that participatory design research collaborations place on community organizations or community members, which should be identified and alleviated to prevent the next stages of exploitation, injustice, and extraction that can subsequently arise. While epistemic burden can happen easily in a wide variety of participatory design research contexts with minoritized groups, the context of epistemic burden through data centering is unique and underexplored; it assumes that data legitimizes communities' claims and requires both explanation and repackaging of traumatic experiences. The substantial burden that arises from such data-centered participatory design research projects risks creating a cycle of collaboration that fuels distrust and prevents meaningful and long-lasting outcomes that truly support and center communities.

In this paper, we use the concept of epistemic burden as a tool for highlighting the harm that can take place in participatory design research, particularly when this engages with minoritized communities and activists through a data-centered approach. We see this as a contribution to work at the intersection of HCI and data justice, an emerging research paradigm that concerns "how social justice can be advanced in a datafied society" [15]. Epistemic burden gives a name to the collective issues of knowledge extraction and uneven power dynamics that place a burden on communities for participating in this type of research. The term is a useful lens for thinking through the issues of this method that have been highlighted recently in HCI, and can help us more clearly identify and alleviate the roots of these issues. Examining data-centered participatory design research through the lens of epistemic burden encourages a sensitivity to the power dynamics of resource and knowledge flows and the clash in fundamental values between community organizations and academic and industry/design researchers, in order to encourage researchers to call into question our approaches to participatory design research. Epistemic burden illuminates what community members are being asked to do within these research dynamics, how it serves or doesn't serve them, and how it aligns or doesn't align with their goals.

For the case of data-centered projects, one solution may be to rethink the purpose and value of data in community organizing and activism more generally, and adjust participatory design research projects accordingly. After further defining epistemic burden and reviewing past work in $\mathrm{HCI}$ on issues in participatory design research, we will use two case studies drawn from our previous work with anti-police brutality community organizations to demonstrate epistemic burden and discuss how to appropriately identify and reflect on this concept to prevent future cycles of exploitation.

\section{LITERATURE REVIEW}

\subsection{Epistemic Burden}

We draw from literature in cultural studies, feminist philosophy, and social epistemology to describe the characteristics and mechanisms of epistemic burden, encapsulated in literature on epistemic injustice and epistemic oppression. Fricker [22] characterizes epistemic injustice as having two faces 1) testimonial injustice in which privileged groups do not accept the oppressed group's testimony of the exploitation they face and engage in calls for "objective" evidence [32], and 2) hermeneutical injustice in which the privileged 
call upon members of the minoritized group to educate them on the oppression they face despite having at their disposal the knowledge, time, ability and other epistemic resources necessary to educate themselves [7, 22, 34]. As in Hall's [25] Encoding/Decoding model of power dynamics in communication, privileged groups shape and normalize interpretative frames that are inadequate for accessing and describing the injustices faced by groups placed at a structural disadvantage. The privileged are able to maintain their power by any combination of feigning ignorance, discrediting marginalized perspectives, and requiring the non-dominant group to expend their own epistemic resources to combat being silenced and disenfranchised [25, 35]. Audre Lorde's [34] "The Master's Tools Will Never Dismantle the Master's House" framed hermeneutical injustice as "an old and primary tool of all oppressors to keep the oppressed occupied with the master's concerns" whether the use of this tool was intentional or not. In this vein, Dotson argues that epistemic oppression is "a persistent and unwarranted infringement on the ability to utilize persuasively shared epistemic resources that hinders one's contributions to knowledge production" [18], depleting the marginalized interlocutor's epistemic agency, or the capacity to wield, revise, and expand shared knowledge within their own communities [22, 35].

Epistemic burden, then, is a type of epistemic oppression that occurs when the privileged demand education from the oppressed in a way that compounds the burden placed on them, while bestowing benefits to the privileged. This burden can include uncompensated epistemic labor that prioritizes the needs of the privileged and exploits the labor of the marginalized, resulting in three outcomes of epistemic burden: 1) diverting the energy of the marginalized to educating the privileged when that energy could have been spent on more productive activities for themselves or within their own communities, 2) privileged interlocutors respond to the stories of the oppressed with hostility, often wielding stereotypes to accuse the marginalized educator as inarticulate, angry, or unreasonable, and 3) in the event that the marginalized educator's labor inspires the privileged to begin to work to undermine oppressive systems, the privileged receive social recognition from their newfound dedication to dismantling oppression while the marginalized, who have paid for this outcome with their own epistemic resources, remain unrecognized because this work is "expected of them" $[1,7]$.

\subsection{Participatory Design Challenges}

An interest in race and minoritized communities appears in HCI research, as well as in ICT4D and related design subdisciplines, although such concerns have not historically been foregrounded. To this end, researchers in HCI have called for the inclusion of impacted communities themselves in processes of design, drawing on methodologies such as action research, cooperative inquiry and participatory processes of value-sensitive design [29] [9]. Action research (AR) and participatory action research (PAR) explicitly put community participants at the center of research, working with them to propose interventions to local problems, then implement and test these designs, and take part in the analysis and write-up of research results, which researchers share with everyone involved [28]. Similar to these democratic and collaborative research methods, participatory design (PD) valorizes researchers engaging in ongoing negotiation or configuration with community participants to determine control over setting the research agenda [48]. Yet while AR and PAR can entail a range of interventions - new policies or program, new administrative roles, as well as new technological designs - within PD, these collaborative processes typically end with the creation of a designed artifact, products, or system [10] [48]. Researchers in HCI have touted PD in minoritized communities for the psychological benefits it confers to participants in the form of empowerment and the improved outcomes it promises designers in the form of "desired product innovation” [30].

Despite a sustained commitment to PD approaches, social computing research has long struggled to meaningfully and authentically engage with minoritized communities, especially workingclass communities of color [26, 38, 50]. Participatory design projects are frequently developed by researchers from outside minoritized communities, a dynamic that overdetermines the results of design and leads to research fatigue among the putative beneficiaries of such projects $[11,17]$. Even the most successful PD projects face challenges over equity, voice, and recognition of a given community's strengths [3, 6]. Harrington et al. [26] argue that participatory design with minoritized communities risks centering the preconceived solutions of designers and other elites, a bias that limits "social action initiatives beyond workshop participation." This continued struggle around inappropriately centering academic solutions and authentic engagement are both key factors in the presence of epistemic burden in PD research. This paper builds on growing interest in and critique of PD by using epistemic burden to concretely identify and define the core issues, expose the clashes of values and power dynamics, and offer a path toward resolution.

\subsection{Anti Design}

Recent work in design activism sees promise in organizing efforts like "\#TechWontBuildIt" as tech employees refuse to work in protest of their employers' contracts with U.S. carceral systems, including the work of the Immigration and Customs Enforcement (ICE) agency [12]. Certainly private sector tech workers should have a say in what they work on, but as Graeff [24] notes, there should also be more thorough normative and practical discussions of what constitutes pro-social design and technology work to begin with. Clearly, not all problems can be fixed with technology and design is not inherently good for any particular group, actor, or person. First, though one can design something to solve a certain intractable design problem, that is not justification to build technology, especially if it is to be deployed into or on "society." Second, many societal problems have deep cultural and structural roots that design solutions alone cannot address. A well-known example is the case of predictive algorithms in the context of policing [44]. In other words, we need to create a design culture of pro-social engagement that includes being able to recognize when and to whom a technology will be harmful, as well as be able to refuse and dismantle harmful design work in a pro-social manner [42]. Within these discussions, there are many questions of whose knowledge, needs, and power should be privileged and how to create a space in which these discussions can happen in meaningful ways that do not generate or compound harm. These are difficult discussions, but the design 
community should not dismiss them out of hand, simply because they are difficult. Epistemic burden is a conceptual tool that helps initiate these conversations and reflections, by enabling a way to identify and acknowledge exploitation, extraction, and injustice that may be taking place in participatory design collaborations. In turn, this process ideally gives us better traction and clarity to evaluate when such collaborations and relationship dynamics are doing more harm than good, and/or what we can shift or adjust to mitigate some forms of harm.

\section{RESEARCH QUESTIONS AND METHODOLOGY}

This paper centers on one primary research question and two subquestions that help examine and demonstrate the concept of epistemic burden in participatory design research. The primary research question speaks to the ultimate goal of this work: to start a discussion about epistemic burden in participatory design research with minoritized communities, specifically data-centered projects, as a way to identify key issues and their root causes, and begin outlining ways to alleviate and avoid these issues through new approaches. The sub-questions address different aspects of using the concept of epistemic burden to avoid further harms through our research practices. The significance of these questions lies in their contributions to a growing area of expertise in $\mathrm{HCI}$ and data justice to help produce research in service of communities, and their ability to encourage active reflection and intentional collaborative research practice. The sub-questions are directly tied to the case study descriptions and analysis, and combine with the design implications to ultimately address the overarching primary question.

- How can we as academics and design researchers avoid perpetuating the cycle of burdening community participants through our approaches to design research collaborations?

- How can the concept of epistemic burden help us identify different harms that participatory design research methods can perpetuate?

- How can we use an analysis of epistemic burdens to steer our approach to the least-harmful, appropriate methods?

Below we analyze two case studies to explore these research questions. We use the theoretical perspectives described above to bound and examine our cases as two empirical examples of the epistemic exploitation potential in data-centered participatory design research. The case study methodology is useful here for comparative analysis, which can reveal analytically significant distinctions and similarities between units. While some case study analyses take a more positivist approach, setting out to unearth general propositions or universal statements, we use the case study methodology more reflexively - not to control variables to make predictions, but to pluralize details and develop theory processually. Constant feedback between analyses and theory allows the researcher to adjust original assumptions to accommodate new findings, leading to richer and more nuanced understanding. To challenge the typical aim of sociological methods to produce general types, we propose theory building as a self-reflexive conversation to develop meaning in practical, situated activities. We believe this iterative movement between data analysis and concept development, between evidence and interpretation, overall leads to a greater understanding of our object of study.

We also embrace interpretation and experiential data, and case studies offer a valuable alternative to quantitative techniques that abstract phenomena from their real-life context. Lucy Suchman [47], who has used in-depth cases to look at technology adoption and use, rejects the idea that her analysis can provide a general, generic description or model that is not also embodied and embedded in particularities of the researcher's context. Certain data can only be produced by experiential observation, which is necessarily variegated and specific to particulars of time and place. Rather than seeking laws or essences, case studies proliferate the variables comprising the bounded case and seek to mirror the abundance of lived life. Because the cases described below entail personal observations and conversations reported through narratives, we do not believe the subjectivity of the researchers can be disentangled from the study. While this methodology is vulnerable to criticism common to many types of qualitative study - that it lacks generalizability, a lack of reliability, and the intrusion of bias - case studies are useful for illuminating the atypical, the processual, and the emergent over long periods of time. The specificities and richness of observed detail can be a valuable (and quite powerful) means to knowledge.

In the next section we look at two case studies that occurred in two different time periods, one in 2014 and another in 2019. Our case study data entailed field notes taken from participant observation of a community event hosted by four of the authors in the first example, and unstructured interviews with community organizers by the fifth author in the second case. For analysis, we asked whether, in either case, we could find instances of epistemic burden in the form of knowledge extraction and legitimizing through data production.

\section{CASE STUDIES}

\subsection{UCLA POIH Project}

Four of the five authors of this paper began the police-officerinvolved homicide (POIH) project in 2014 [14], as a reaction to police officer Darren Wilson's murder of Michael Brown. This event cast national attention on the multiple instances of police officers killing unarmed Black people and rekindled longstanding concerns over racist policing. As calls for reckoning with racism embedded in civic systems grew louder, news outlets reported that there was no trusted official database tracking how many people were killed by police across the United States at the time, or historically [14, 21]. The phenomenon of racist police violence concerned the group greatly. The angle that somehow the data did not verify racist and violent police tactics seemed to be a place that we, as researchers, could intervene. We were trained to view data as political [23, 46], and we wanted to see how this was the case with the data capturing police homicides in Los Angeles County.

A frequent source of obfuscation of the real number of police officer- involved homicides in a given period is poor or incomplete documentation [14, 40]. Unsurprisingly, we traced persistent, extensive, and complex issues of power reflected in official federal, state, and local Los Angeles County's data collection and curation efforts around police violence. Police departments are not compelled by law to report incidents, and rules for reporting differ by state, while incidents happening on federal land and reservations 
are not documented. When instances of police committing homicide are documented, that information is incomplete or does not seem to match across official data sets, especially with information regarding the victim's race, age, and address. Last, but not least, there is a significant time lag in the data's availability - e.g. in 2015, the most recent data from the FBI's Supplementary Homicide report was from 2012. These data sets were out-of-date, difficult to parse and compare, and could not be used to provide a basis for any sort of argument about the prevalence of violent racist policing. Each of these findings supported the idea that making these data sets available was not a democratic exercise in government transparency, but rather a way for state and federal governments to exempt themselves from accountability.

Even as we performed this first round of research we were aware of the fact that testimonial injustice existed, even though we did not understand it in those terms at the time. We knew the calls for data around the phenomenon of racist police violence was in some way a prejudicial disavowal of the testimonies, activism, and informal evidence that people living in targeted communities had been collecting and disseminating for years [32]. In our attempt to honor this fact, we looked to our academic field for ways to value lived experience, which was not our own. Following trends in using PD to engage issues of inequity, we invited the public to participate in making sense of the official data we had collected and collaborate in our preliminary analyses of it. Over 50 people from the community joined us, including grassroots organizers, instructors, students, and residents from across Los Angeles. We found that while there was much to talk about regarding the poor quality of official data and the various excuses for the poor quality, local community groups were doing their own data collection and research on police violence. This data looked different from the official data with which we had been engaged. The data were entirely qualitative or included narrative accounts alongside geographic and demographic data - organizers collected these narratives by going door-to-door in neighborhoods where police violence took place. Second, the data was only available as a PDF on the groups' website. Instead of wanting to create better data systems to push for law enforcement accountability, the organizers did not trust the government to honor justice in these endeavors. Instead, these groups wanted the public to understand and listen to what was happening in their communities.

Indeed, perhaps the biggest takeaway from this engagement was that two community groups who took part in our workshop did not wish to reform law enforcement or carceral systems' production and use of data; they had no faith that pushing for law enforcement accountability would promote positive outcomes for communities most often targeted by the police. Instead the groups articulated that they push for abolition of structures of police violence, which includes data introduced with hand-waving declarations to make policing more just, because the institution of law enforcement itself is predicated on perpetuating systemic inequalities $[2,5]$. In their experience, data-driven technologies, especially those with stated goals to reform law enforcement, only justify, perpetuate, and entrench those unjust systems [40].

While our intervention was an honest attempt to grapple with this complex and difficult phenomenon, it was far from perfect. We started relationships with community groups we became familiar with through the project. The POIH group held a public panel with community groups and continued to be involved with the groups, assisting with research and organizing as long as we lived in Los Angeles. Successor research projects sought to track campus police harassment [41]. However, the nature of academic careers took all but one of us away from UCLA and Los Angeles where we could best assist with local Los Angeles policing issues. The tension between our presumptions about the appropriate use of data for these communities and their own visions is an example of two kinds of epistemic burden: our centering of federal, state, and general policy-related data as a solution implied greater legitimacy of our approach, and diverted attention away from the active work being conducted by the community organizations.

In the next section, we turn to a final case that concerns a community PD project, one that set out to offer working-class Black and Latinx community members the benefits of expertise from computer scientists and data professionals.

\subsection{Data Justice Database}

This section focuses on an interview conducted in the course of a larger, ongoing PD project inspired by data justice, preliminary results of which are forthcoming in other publications [15]. Data justice can serve as a useful lens to draw together multidisciplinary research on community-based organizations and the ethics of computing [39]. The first phase of this research project, completed in January of 2020, involved the construction of a Data Justice Database, a set of profiles of 73 community-based organizations in Southern California that use data in pursuit of their missions and explicitly engage in work that involves some articulation of social justice. From the larger list, student researchers identified a small set of cases to conduct interviews for the purpose of identifying partners for local community-based participatory design projects. They sent invitations to 12 organizations to sit for a one-hour interview; eight responded affirmatively and four did not respond. From these candidate cases, five were selected based on the organization's stated willingness to partner with academic researchers. The interview summary and excerpts that follow are drawn from a single interview in that data collection, a March 2020 interview with a youth advocacy organization referred to in this paper as Justice Youth Initiative (JYI). Like other political organizations based in working-class communities of color, JYI experienced a number of challenges related to the potentials and risks of data-mediated activism [13]. While this single case is not meant to stand in for all community organizations, it does point to some particularities of working-class communities of color related to epistemic burden and, promisingly, a potential path toward more equitable engagements.

As is common in PD research, the Data Justice Database project incorporated interviews aimed at systematically describing the beneficiary community's needs in order to begin "a cycle of prototyping, testing, and re-design in order to work towards solutions that are effective in fitting with user and community needs" [19]. These interviews revealed that, from the perspective of one particular community organizer, harm related to exploitative practices that occurred in the aftermath of participatory design research was ongoing and continual. Researchers who intended to start new data-oriented design projects in working class communities of 
color found a wary reception from an organization that had served as the site of earlier ameliorative efforts, efforts that left in their wake a skeptical audience. In addition to the types of epistemic burden discussed in earlier sections of this paper, this iteration of community-academic exchange turned on the unjust distribution of reputational and financial rewards available to different kinds of participants. In short, marginalized community members who have contributed knowledge, labor, and data to a design project remain uncompensated because this work is expected of them [1,7].

Justice Youth Initiative participated in the hackathon inspired by the Ferguson uprisings run by several of this paper's co-authors and described in the previous section. In this way, this second case study offers a rare opportunity to learn about epistemic burdens that might emerge after the end of an ostensibly successful communitybased PD project. In the intervening years, the organization had grown to include two full-time staff and a dozen fellowship-funded, project-based temporary workers. The organization had also developed considerably in terms of its use of digital tools. One area of success for the organization involved records of officer-involved homicides. Led by families of people killed by police, the organization had successfully lobbied the state of California to make reports of such killings subject to public records requests. Using those reports, volunteers had developed a process which involved reading over police reports and transcribing that information into a database. Organizers also collected other kinds of information, including accounts of witnesses and surviving family members. The JYI organizer expressed interest in having the support of academic computer science and data science students and faculty, but expressed deep ambivalence about how such collaboration might help the organization and the broader community.

In an interview with two student researchers, a youth organizer explained the importance of community labor in populating this database. This organizer explained the importance of keeping the names of people killed by police connected to other, officially recognized forms of data, such as badge numbers, report indexes, and legal documents. Above all, the organizer explained the importance of keeping the victims' names connected to the work that community organizers and surviving families had done to acknowledge the death of a person, including advocating for changes to state law that expanded the rights of citizens to request public records related to officer-involved homicides.

However, this organizer's assessment on the database constructed with the help and input of academics and other kinds of experts spoke of deep resentment. She indicated a number of problems that the organization encountered: academics, journalists, and other community organizations frequently consulted the database or used it without crediting the organization. These other stakeholders frequently made reference to police violence and officerinvolved homicides, but did so without mentioning the names of the victims. This organizer specifically criticized the actions of academic researchers in this space.

"Academia is inherently exploitative... Often times, you have professors who aren't directly impacted, and they don't center the family members. They [academics] started submitting for grants and were getting funding to do this type of work, and it completely wiped away all the work the families had been doing for years, who did this not because it was research, or because it was their job, it was because it affected them directly... So I wish academia was more tuned to that because it's annoying."

In terms of epistemic burden, the organizers rebuke shows how demands placed on racialized communities attenuate the utility of community-based research, including participatory design. Racialized and minoritized communities frequently host communitybased research, but these interactions tend to revisit frequent players and sites, such that these sites become subject to research fatigue [11]. Certainly, many academic researchers genuinely care about racialized and minoritized communities, but there are powerful contextual factors that contribute to the shape and contour of community-based research: state disinvestment in Black and Latinx neighborhoods, a declining and increasingly privatized public sector, and the class and racial composition of the professional and academic research community. All of these factors give communitybased research, including participatory design research, its particular character and create conditions that give rise to the exploitation our respondent was foregrounding. Equally important however, is the economy of credit: the metrics used to attribute success or failure of an individual academic (authorship, publication, citation, media coverage, funding) do not easily accommodate the tangled and shared intellectual space of community work. More, the economy of academic reward works to the relative advantage of academic researchers: communities themselves have less power to press for acknowledgement of community member input into intellectual work, particularly if that work takes the form of a digital tool or a dataset, which might travel quite widely beyond the site of its creation or the intentions of its many authors. Perhaps the most glaring disconnect between the acknowledged importance of community-based research and the realities of academic work is in funding. Simply put, from the perspective of community members, academic research is lucrative on a scale that is difficult to justify. Working-class communities of color, structurally deprived of wealth, do not benefit from the same opportunity to earn grants as academic researchers. Funding from state agencies and philanthropic organizations itself is a site of extreme inequality, one that again works to the benefit of credentialed, institutionally affiliated researchers [27].

There are many complicated and conflictual motivations for doing research in minortized communities, just as there are many reasons why community members might or might not wish to partner with particular researchers. As postcolonial scholars have frequently remarked in criticizing forms of participatory research, knowledge, including design research, is shaped by power [31]. Our point here is not that participatory design research should be abandoned. To the contrary, our argument is that in terms of structural oppression, design is unexceptional in that it is, like many other forms of knowledge work, deeply enmeshed in the thinking and practices that reproduce inequality. By acknowledging the many forms of epistemic burden placed on minoritized communities, researchers can center the long history of oppression that informs such work, one way of moving toward more equitable partnerships [26]. While no single solution can alleviate this status quo, 
Table 1: How different instances of epistemic burden and injustice unfold in our case studies.

\begin{tabular}{|c|c|c|}
\hline Epistemic Burden & Injustice & Case Study \\
\hline $\begin{array}{l}\text { 1: diverting the energy } \\
\text { of the marginalized to } \\
\text { educating the } \\
\text { privileged. }\end{array}$ & $\begin{array}{l}\text { Hermeneutical } \\
\text { injustice }\end{array}$ & $\begin{array}{l}\text { UCLA POIH } \\
\text { Project }\end{array}$ \\
\hline $\begin{array}{l}\text { 2: the privileged see } \\
\text { the marginalized as } \\
\text { inarticulate, angry, or } \\
\text { unreasonable. }\end{array}$ & $\begin{array}{l}\text { Testimonial injus- } \\
\text { tice }\end{array}$ & $\begin{array}{l}\text { UCLA POIH } \\
\text { Project }\end{array}$ \\
\hline $\begin{array}{l}\text { 3: the privileged } \\
\text { receive social } \\
\text { recognition, while the } \\
\text { marginalized remain } \\
\text { unrecognized. }\end{array}$ & $\begin{array}{l}\text { Reputational/capital } \\
\text { injustice }\end{array}$ & $\begin{array}{l}\text { Data Justice } \\
\text { Database }\end{array}$ \\
\hline
\end{tabular}

the community organizer interviewed at the top of this section offered something of a way forward in calling for the recognition of the experiential knowledge of community members. This call echoes work in feminist science studies for an approach to knowledge creation that acknowledges the situated and partial nature of all knowledges. From this perspective, the creation of more equitable relations between researchers and community members requires a more modest approach to knowledge creation, one that calls on researchers to "become modest and do the hard work of attending to the specificities of one's situation" [43].

\section{DISCUSSION}

We start this section by discussing our case studies, and reviewing how they relate to different kinds of epistemic burden and produce different kinds of injustice (summarized in Table 1). By doing so, we hope to make the burden we created visible to other data-centered PD researchers. While the primary intent of this paper is to highlight burden and discuss its consequences for communities, we also want our approach to be ameliorative in nature: the overarching goal is to find ways to collaborate with communities that are mutually beneficial. For this reason, we end the discussion with a set of critical questions related to data-centered PD that can help researchers to alleviate epistemic burden in PD with minoritized communities.

Our two case studies show how different kinds of epistemic burdens can unfold in practice. The first case study illustrates an example of testimonial injustice [22,32], in which a privileged group does not accept the oppressed group's testimony of the exploitation they face. We, and the other researchers and journalists who participated in the project, as the privileged group, failed to acknowledge the testimony of the oppressed group by taking seriously neither their call for abolition nor the way they wished to use the data that they produce themselves as forms of evidence. While we were aware of the existence of these issues, we only tangentially engaged with them in both our PD practice and in the academic writing that followed. By concentrating attention and resources towards issues of police reform and government data, we indirectly but effectively rendered the call for abolition and the community's data and approach to data use as "less valuable" or "deserving less attention" compared to the epistemic issues we prioritized and pushed for. Their approach might be seen as more in line with the anti-design solutions outlined in the literature review, and recognizing the epistemic burden we were placing on the community could have helped us come to that realization sooner.

Such instances of testimonial injustice can be understood as a result of the second type of epistemic burden we identified in the literature [1,7]: privileged interlocutors respond to the stories of the oppressed with hostility, often wielding stereotypes to accuse the marginalized educator as inarticulate, angry, or unreasonable. While we were not directly openly or intentionally hostile towards the communities we worked with, we want to recognize that there are many ways in which the oppressed can be diminished by the actions of the privileged, and neglect is one of these. By marginalizing the epistemic priorities of the community members we worked with, we effectively disregarded the actual possibility of employing grassroots qualitative data as valid evidence to document police violence, and of abolition as a valid solution to end structural racial injustice.

The first case study is also an example of hermeneutical injustice $[7,22,34]$, in which the privileged call upon members of the marginalized group to educate them on the oppression they face. In other words, not only did we not take the community organizations' data and solutions seriously, but we also wanted to replace or at least complete them with "better" solutions and data. Based on our positions in academia, particularly within information science and design fields, we were taught to approach this phenomenon as a design problem that could be remedied with enough input from the right types of people and official data sources. Even as we knew data was a rhetorical tool imbued with power and influence, we did not appropriately honor that fact. By attending so intently on correcting the official data record, pointing out where its political faults lie, and thinking through different ways to improve it, we committed a form of hermeneutical injustice. We unintentionally ignored the project that may have been more helpful: using our academic privilege to push for official recognition of the narratives collected by the grassroots groups as the basis for radically changing or even abolishing policing practices as they exist.

In retrospect, even the name we gave the "police-officer involved homicide project" makes it clear that while there was an intense desire to do this type of work correctly, our ability to do so was thwarted by our inexperience, and likely compounded by the dearth of expertise in information science and design fields regarding how to do this work in ways that do not exacerbate extant epistemic burdens. We chose this moniker because this was most often how it existed in the official datasets. We did not know until later that the term "officer-involved homicide" was coined by the LAPD-the very institution presiding over the area we were concerned with, and this term became widespread after the 1979 murder of Eula Mae Love by LAPD police officers [20,33]. The term is confusing, passive, and obfuscates who is doing what to whom, exonerating the officer from guilt in its semantic relationship [8].

A completely different, opposite approach would have been to take the community organizers' approaches, arguments, and data 
as the central focus and foundation of the work, and dedicate our efforts to work with these communities to reach their own goals. For example, we could have conducted a study about preconceptions against abolition as a solution to structural injustice, or we could have provided digital curatorial support for the data collections and for other forms of evidence created by the communities. We could have leveraged our positionality as academics to organize a panel with high level representatives from local institutions, and facilitate a dialogue between them and the community organizers. But this is just speculation, as we will never know what we could have actually done, as we didn't explicitly ask.

We can now clearly see how, in our first case study, hermeneutical injustice is also closely connected to the first type of burden described in the literature review: diverting the energy of the marginalized to educating the privileged $[1,7,34]$. Upon understanding the mechanisms by which epistemic burden proliferates, we see very clearly with the project that by virtue of "inviting diverse community stakeholders" to our campus to discuss the phenomenon, we were asking interlocutors to use their epistemic resources to educate privileged students and faculty, and asked that they engage in these discussions in a place at least one interlocutor described as hostile. In some senses, it was a productive and sustained radicalizing experience, in which the hearts and minds of the privileged interlocutors (the researchers and others in attendance) were opened to other ways of regarding and working through these phenomena. But in the end, it was we, the researchers, who published articles based on our engagement with these groups and our newfound perspectives of working through these problems. We received grants on the basis of this work, and it strengthened cases for our employment in academia. These are immense material gains for us, who were already privileged given our position within academia. Those community members and organizers who attended our event, on the other hand, were seen as fulfilling their roles in representing their community and educating us on the dimensions of the issues that we were researching from perspectives that are and were not valued in our academic field.

The second case study exemplifies a third kind of epistemic burden: the privileged begin to work to undermine oppressive systems and receive social recognition, while the marginalized, who have paid for this outcome with their own epistemic resources, remain unrecognized because this work is "expected of them" $[1,7]$. This kind of epistemic burden was brought to our attention by a community organizer, during an interview with one of the authors of this article. In our analysis of the case study, we noted that this burden produced at least two additional instances of injustice: reputational injustice and capital injustice.

As indicated by the community organizer, academics, journalists, and other community organizations rarely credit the central role that her organization played in producing, curating, and making available the data on police reports hosted in the database. In addition, academics and journalists failed to name the victims in their reports, a best practice that the community organizer particularly cares about and explicitly recommended. On the contrary, the names of the researchers and the journalists received attention: they appeared at the top of articles and reports, they gained citations, they caught the attention of conference organizers and hiring committees, and so on. In this way, the names of the privileged enter a cycle of credit that results in an increase of personal fame and recognition, while organizers' and victims' names received little publicity. We call this an example of reputational injustice. From an academic perspective, a solution to this problem would be to clearly mention and cite within the text of the article the names of organizers who contributed to the production of key resources, or even consider adding community organizers as co-authors of academic articles, or co-presenters at conferences.

The last and most practical instance of injustice that we identified is the one that manifests itself in terms of unequal distribution of capital and resources, as a result of the burden produced by the PD work. Community organizations are well aware of the fact that researchers need to earn grants to conduct research at a certain scale, and that those grants bring wealth to the researchers and to their communities. In this sense, academia is seen as a lucrative machine. They also know that, for the researchers, gaining access to the communities and to their data is a key step in the process of earning a new grant. Finally, community organizations are also aware of the fact that they do not receive any compensation for their collaboration with the researchers, for the access they provide the researcher with, and for the data that they collect, curate and make available to the researcher. A starting point to alleviate this burden could be to budget for funding that can be used to compensate the organizations within the writing of a grant proposal, at very least. For this to happen, funding agencies would have to understand this necessity and agree to provide ad-hoc support. Another way to alleviate this burden would be for the academics to provide free training to community organizers for preparing grant applications for funding opportunities made available by those state and philanthropic agencies who could potentially fund the communities directly.

\section{DESIGN IMPLICATIONS}

As shown in the case studies and discussion, data-centered participatory design research focused on cooperative agenda-setting currently contributes to potentially harmful cycles of collaboration with community organizations and communities more generally, through epistemic burden in the form of knowledge extraction and diversion of energy, legitimizing through data production, and imbalance in distribution of recognition and material gains. The design implications of this realization are manifold, but all center on the necessity of academic, industry, non-profit, and other researchers engaged in this work to fundamentally shift their approach to research framing, guiding, and organizing when conducting participatory design research using data and with minoritized groups. Ultimately, as mentioned by one of the interviewees in the second case study, this necessitates a broad commitment to "organizing ourselves first" before we think about intervening in communitybased participatory design and as we engage in these processes. This fundamentally involves allowing community groups to set the research agenda and terms of engagement. We have outlined the following key steps to this process of organizing ourselves:

(1) Anticipating and Identifying. By organizing ourselves, we start by analyzing the dynamics of knowledge and resource flow that will ensue in the collaboration. A crucial part of this process is speaking with potential community 
organization partners to hear their initial thoughts and/or concerns around potential collaboration. From there, we can decide if changes need to be made to that process, and/or if there is a high risk of extending epistemic burden that would render it inappropriate to pursue PD research methods for a given topic or with a given community or context. This initial analysis necessitates identifying and mapping out the potential epistemic burdens or exploitative situations that may result from our work, and requires the development of concrete plans to mitigate and ideally eradicate those risks.

(2) Reflecting and Deconstructing. This process also involves reflecting on and deconstructing ideas around how and when participatory design research can and should be used, and especially how and when data should be used in design research collaborations. Reflection is needed to determine if the approach will be helpful or supportive, and should involve a concrete reckoning with how a participatory design research approach does or does not ultimately reach the goal of meaningfully and substantially involving and benefiting community members. This could also involve deconstructing initial research plans and ideas set and collaboratively developed with community partners, as shown in our reflection of what different research approaches we might have made in the first case study after further understanding the organizations' core approach.

(3) Rethinking and De-centering. Lastly, organizing ourselves involves the active de-centering of academic contribution in participatory design research collaborations, and especially de-centering of data when needed and desired by relevant communities. For the cases discussed in this paper, this involves examining where clashes and tensions exist between how researchers are thinking about data and framing the importance of the work accordingly, and how community organizations and members are thinking about and desire to use data for their work, if at all. Avoiding epistemic burden necessitates reforming the researcher role as one of support for existing community efforts, rather than the driver of new work that requires significant knowledge extraction without core lasting benefit. De-centering also involves intentional redistribution of material gains and recognition as suggested in solutions to the issues presented in the second case study Ensuring community organization members are setting the research plan and terms of engagement are again a crucial part of this process.

Only after these steps of interrogation, anticipation, reflection, and de-centering through epistemic burden can we meaningfully and successfully collaborate with community members through participatory design. There may be situations still where even after these steps, it may not be useful to try and contribute or "help" community organizations and instead find ways we can organize ourselves as an end goal. Ultimately, we use these design implications to call for a reorientation of academic knowledge production away from primarily providing design "solutions" to community "problems" and toward directly addressing the unexamined political issues involved in academic and design researchers' engagement with minoritized communities.
While we focus here on PD, this paper also has implications for related methodologies of action research (AR) and participatory action research (PAR), methods that involve an open-ended, iterative approach to research and are developed with communities - the outcome is in service of long-term reflection and sustainable change in the research environment, not the success of a single intervention [28]. As mentioned, these methods are already well-attuned to the power dynamics and various roles of the research setting, but here we could offer AR and PAR researchers more conceptual tools for carrying out data-oriented research with minoritized communities in particular. Likewise, we also bring PD more in line with AR, in the sense that we also call on more reflection and learning after the design process, to influence further interventions or stages of design, and so adopting AR's more iterative approach.

\section{STUDY LIMITATIONS \& NEXT STEPS}

While the two case studies described in this paper are strong examples of the potential to extend epistemic burden in data-centered participatory design research, they represent a small slice of the potential examples that could be reviewed to further demonstrate this concept. As a newly introduced concept to HCI, this paper represents just the beginning of an ideally more nuanced and developed conversation within the field, building on previous critiques and calls to action for researchers who engage in participatory design work. Similarly, the idea of "organizing ourselves" as a solution to issues of epistemic exploitation and the cycles of extraction and burden that result from this process are also relatively new concepts, and require further exploration and nuance to be fully actionable for the intended audience of this paper.

To address these limitations, next steps for this work include collecting further case studies to build up a database of examples to further provide evidence for and strengthen this central argument. New contexts outside of anti-police brutality but still centered on data use, and even some non-data-centered examples can continue to help develop the concepts presented in this paper to continue to grow its relevance and application. A second major next step includes developing a more concrete resource to continue to make this work adaptable and actionable that builds on the design implications section and the suggestions put forth there. While we provided a necessary starting point for discussing the steps of anticipation, reflection, and de-centering that are needed as a solution to the problem identified here, these are still only starting points, and do not yet represent a robust plan that can be easily adopted or used by those interested in this work.

Thus, a crucial next step is a more tangible output that can accompany this paper, namely a digital resource outlining a process for conducting the "organizing ourselves" steps. This resource will include key questions and exercises for academic organizing around the prevention of exploitation through epistemic burden in participatory design research. This type of resource can be easily paired with further work on the database of case studies, by using more varied examples to think through how to identify and anticipate potential epistemic burden in broader contexts and more varied researcher roles. This resource may even be used as part of a workshop series encouraging researchers engaged in participatory design research to work through these issues collaboratively and 
grow the resource consequently. These activities and next steps overall serve the primary goal of preventing epistemic burden in our work through adequate preparation and intention.

\section{CONCLUSION}

In this paper, we have introduced the concept of the epistemic burden, and demonstrated how it can be used as a tool to identify persistent problems that occur when researchers pursue communitybased PD projects. Participatory design research seeks to build opportunities for academics and community organizations to work in equal partnership with each other, and to engage in research in a way that enables community stakeholders to shape the research agenda so that it best serves their needs and leads to lasting positive community outcomes. However, as we demonstrate through reflections in two case studies of our own past work, our approach to participatory design research and the role we play in shaping an agenda can often fall short of a community's goals, and in turn place a burden on community organizations we partner with in three distinct ways.

In the first case, we reflected on how our work with anti-police brutality organizations contributed to the first two kinds of epistemic burden we have outlined, where our work in some ways diverted energy away from original causes and our pre-disposed focus on data was built on the assumption that it was needed to legitimize the organizations' causes. Though definite gains came out of this partnership, more work was needed on our end to help further prevent these types of burdens. In the second case study, we discussed the third type of epistemic burden, where scholars received social recognition that community organizations did not, even after providing labor and assistance in the scholarship. Since at least one of the organizations between these two projects was the same, our lack of identifying and highlighting epistemic burden and aligning it with our plans created a cycle of continued burden and associated injustice. Through our reflections, we demonstrate how identifying and acknowledging epistemic burden is crucial work that participatory design researchers need to do in order to adequately prepare and "organize ourselves" before seeking out partnership with community organizations.

As outlined in the discussion, had we done this work beforehand, we would have gone into our partnerships differently, and ideally would have prevented the propagation of burden. In doing this work of reflecting upon, identifying, analyzing epistemic burden in our community organization relationships in order to resolve core burdens and injustices we see, we show how researchers might more thoughtfully engage in participatory design research to contribute to community organizations' work on their own terms. The organizations we worked with in these case studies have been fighting for true acknowledgement, recognition, and response to their lived realities of police violence and socio-political oppression. We hope that the concept of epistemic burden and the resulting academic organization that it should enable allows us to prevent further burden and extraction from community organizations, and allows them to focus on their needs and goals and work with us as academics and design researchers in supportive roles.

\section{ACKNOWLEDGMENTS}

The authors would like to thank their many community partners outlined in the case studies, including the Stop LAPD Spying Coalition, and Our Data Bodies, the Youth Justice Coalition, and the Los Angeles Community Action Network, as well as community members who participated in research events. Their gracious collaboration shaped the impetus for this paper. We'd also like to thank University of California - Irvine informatics PhD students Lucy Pei and Bono Olgado for their research support.

\section{REFERENCES}

[1] Sara Ahmed. 2007. A phenomenology of whiteness. Feminist Theory 8, 2 (Aug. 2007), 149-168. https://doi.org/10.1177/1464700107078139 Publisher: SAGE Publications.

[2] Michelle Alexander. 2012. The New fim Crow: Mass Incarceration in the Age of Colorblindness. The New Press, New York.

[3] Karl Baumann, Benjamin Stokes, François Bar, and Ben Caldwell. 2017. Infrastructures of the Imagination: Community Design for Speculative Urban Technologies. In Proceedings of the 8th International Conference on Communities and Technologies. ACM, Troyes France, 266-269. https://doi.org/10.1145/3083671.3083700

[4] Christoph Becker, Ann Light, Chris Frauenberger, Dawn Walker, Victoria Palacin, Syed Ishtiaque Ahmed, Rachel Charlotte Smith, Pedro Reynolds Cuéllar, and David Nemer. 2020. Computing Professionals for Social Responsibility: The Past, Present and Future Values of Participatory Design. In Proceedings of the 16th Participatory Design Conference 2020-Participation (s) Otherwise-Volume 2. 181-184.

[5] Ruha Benjamin. 2019. Race After Technology: Abolitionist Tools for the New fim Code (1 edition ed.). Polity, Medford, MA.

[6] Laura Benton, Asimina Vasalou, Rilla Khaled, Hilary Johnson, and Daniel Gooch. 2014. Diversity for design: a framework for involving neurodiverse children in the technology design process. In Proceedings of the 32nd annual ACM conference on Human factors in computing systems - CHI '14. ACM Press, Toronto, Ontario, Canada, 3747-3756. https://doi.org/10.1145/2556288.2557244

[7] Nora Berenstain. 2016. Epistemic Exploitation. Ergo, an Open Access fournal of Philosophy 3 (2016). https://doi.org/10.3998/ergo.12405314.0003.022

[8] Devorah Blachor. 2020. How to Use the Past Exonerative Tense to Uphold White Supremacy. https://www.mcsweeneys.net/articles/how-to-use-the-pastexonerative-tense-to-uphold-white-supremacy

[9] Alan Borning and Michael Muller. 2012. Next Steps for Value Sensitive Design. In Proceedings of the SIGCHI Conference on Human Factors in Computing Systems (Austin, Texas, USA) (CHI '12). Association for Computing Machinery, New York, NY, USA, 1125-1134. https://doi.org/10.1145/2207676.2208560

[10] Tone Bratteteig and Ina Wagner. 2016. What is a participatory design result? In Proceedings of the 14th Participatory Design Conference on Full papers - PDC '16. ACM Press, Aarhus, Denmark, 141-150. https://doi.org/10.1145/2940299.2940316

[11] Tom Clark. 2008. 'We're Over-Researched Here!': Exploring Accounts of Research Fatigue within Qualitative Research Engagements. Sociology (Oct. 2008). https://doi.org/10.1177/0038038508094573 Publisher: SAGE PublicationsSage UK: London, England.

[12] Sasha Costanza-Chock. 2020. Design fustice: Community-Led Practices to Build the Worlds We Need. The MIT Press, Cambridge, MA.

[13] Roderic Crooks and Morgan E. Currie. 2021. Numbers Will Not Save Us: Agonistic Data Practices. The Information Society Forthcoming (2021).

[14] Morgan Currie, Britt S. Paris, Irene Pasquetto, and Jennifer Pierre. 2016. The conundrum of police officer-involved homicides: Counter-data in Los Angeles County. Big Data \& Society 3, 2 (Dec. 2016), 2053951716663566. https://doi.org/ $10.1177 / 2053951716663566$

[15] Lina Dencik, Arne Hintz, Joanna Redden, and Emiliano Treré. 2019. Exploring Data Justice: Conceptions, Applications and Directions. Information, Communication \& Society 22, 7 (June 2019), 873-881. https: //doi.org/10.1080/1369118X.2019.1606268 Publisher: Routledge_eprint: https://doi.org/10.1080/1369118X.2019.1606268.

[16] Catherine D'Ignazio, Erhardt Graeff, Christina N Harrington, and Daniela K Rosner. 2020. Toward Equitable Participatory Design: Data Feminism for CSCW amidst Multiple Pandemics. In Conference Companion Publication of the 2020 on Computer Supported Cooperative Work and Social Computing. 437-445.

[17] Carl DiSalvo. 2015. Adversarial design. OCLC: 907512742.

[18] Kristie Dotson. 2014. Conceptualizing Epistemic Oppression. Social Epistemology 28, 2 (April 2014), 115-138. https://doi.org/10.1080/02691728.2013.782585 Publisher: Routledge_eprint: https://doi.org/10.1080/02691728.2013.782585.

[19] Paul Dourish, Christopher Lawrence, Tuck Wah Leong, and Greg Wadley. 2020. On Being Iterated: The Affective Demands of Design Participation. In Proceedings of the 2020 CHI Conference on Human Factors in Computing Systems (CHI '20). 
Association for Computing Machinery, New York, NY, USA, 1-11. https://doi. org/10.1145/3313831.3376545

[20] Max Felker-Kantor. 2020. Liberal Law-and-Order: The Politics of Police Reform in Los Angeles. Fournal of Urban History 46, 5 (Sept. 2020), 1026-1049. https: //doi.org/10.1177/0096144217705462 Publisher: SAGE Publications Inc.

[21] Reuben Fischer-Baum. 2014. Nobody Knows How Many Americans the Police Kill Each Year. http://fivethirtyeight.com/features/how-many-americans-thepolice-kill-each-year/

[22] Miranda Fricker. 2007. Epistemic Injustice: Power and the Ethics of Knowing Oxford University Press, Oxford, UK. https://www.oxfordscholarship.com/view/ 10.1093/acprof:oso/9780198237907.001.0001/acprof-9780198237907 Publication Title: Epistemic Injustice.

[23] Lisa Gitelman (Ed.). 2013. Raw Data Is An Oxymoron. MIT Press, Cambridge, MA.

[24] Erhardt Graeff. 2020. The Responsibility to Not Design and the Need for Citizen Professionalism. Computing Professionals for Social Responsibility: The Past, Present and Future Values of Participatory Design (May 2020). https://pdc2020cpsr.pubpub. org/pub/vizamy14/release/1 Publisher: PubPub.

[25] Stuart Hall. 2001. Encoding/Decoding. In Media And Cultural Studies: Keyworks, Meenakshi Gigi Durham and Kellner (Eds.). Blackwell Publishing, Ltd., Malden, MA.

[26] Christina Harrington, Sheena Erete, and Anne Marie Piper. 2019. Deconstructing Community-Based Collaborative Design: Towards More Equitable Participatory Design Engagements. Proceedings of the ACM on Human-Computer Interaction 3 CSCW (Nov. 2019), 216:1-216:25. https://doi.org/10.1145/3359318

[27] Iain Hay and Samantha Muller. 2014. Questioning generosity in the golden age of philanthropy: Towards critical geographies of super-philanthropy. Progress in Human Geography 38, 5 (Oct. 2014), 635-653. https://doi.org/10.1177/ 0309132513500893 Publisher: SAGE Publications Ltd.

[28] Gillian R. Hayes. 2011. The Relationship of Action Research to Human-Computer Interaction. ACM Trans. Comput.-Hum. Interact. 18, 3, Article 15 (Aug. 2011), 20 pages. https://doi.org/10.1145/1993060.1993065

[29] John Heron. 1996. Co-Operative Inquiry: Research Into the Human Condition. SAGE Publications, Thousand Oaks, CA.

[30] Sofia Hussain, Elizabet Sanders, and Martin Stienert. 2012. Participatory Design with Marginalized People in Developing Countries: Challenges and Opportunities Experienced in a Field Study in Cambodia. International fournal of Design 6, 2 (2012), 91-109.

[31] Julia E Janes. 2016. Democratic encounters? Epistemic privilege, power, and community-based participatory action research. Action Research 14, 1 (March 2016), 72-87. https://doi.org/10.1177/1476750315579129 Publisher: SAGE Publications.

[32] Candice Lanius. 2015. Fact Check: Your Demand for Statistical Proof is Racist. https://thesocietypages.org/cyborgology/2015/01/12/fact-check-yourdemand-for-statistical-proof-is-racist/

[33] John Lehry. 2016. "Officer-Involved” Obfuscation. https://jacobinmag.com/2016/ 09/eula-love-officer-involved-shooting-black-lives-matter/

[34] Audre Lorde. 1984. The Master's Tools Will Never Dismantle the Master's House. In Sister Outsider: Essays and Speeches. Crossing Press, Berkeley, CA, 110-114.

[35] José Medina. 2013. The Epistemology of Resistance: Gender and Racial Oppression, Epistemic Injustice, and the Social Imagination. OUP USA. Google-Books-ID: j_nUeoyASq8C.
[36] Toni Morrison. 1975. A Humanist View. https://www.mackenzian.com/wpcontent/uploads/2014/07/Transcript_PortlandState_TMorrison.pdf

[37] José Esteban Muñoz. 1999. Disidentifications: Queers of Color and the Performance of Politics. University of Minnesota Press.

[38] Ihudiya Finda Ogbonnaya-Ogburu, Angela D.R. Smith, Alexandra To, and Kentaro Toyama. 2020. Critical Race Theory for HCI. In Proceedings of the 2020 CHI Conference on Human Factors in Computing Systems. ACM, Honolulu HI USA, 1-16. https://doi.org/10.1145/3313831.3376392

[39] B.S. Olgado, L. Pei, S. Rana, K. Vasques, E. Partida, and Roderic Crooks. 2021. Response-able Ethics in Computer Science: Reflections on an NSF-REU Program. Computer Science Education Under Review (2021).

[40] Britt S. Paris and Jennifer Pierre. 2017. Bad Data. https://culanth.org/fieldsights/ 1107-bad-data

[41] Britt S. Paris and Jennifer Pierre. 2017. Naming Experience: Registering Resistance and Mobilizing Change with Qualitative Tools. InterActions: UCLA fournal of Education and Information Studies 13, 1 (2017). https://escholarship.org/uc/item/ 02d 9 w4qd

[42] James Pierce. 2012. Undesigning technology: considering the negation of design by design. In Proceedings of the 2012 ACM annual conference on Human Factors in Computing Systems - CHI '12. ACM Press, Austin, Texas, USA, 957. https: //doi.org/10.1145/2207676.2208540

[43] Jenny Reardon, Jacob Metcalf, Martha Kenney, and Karen Barad. 2015. Science \& Justice: The Trouble and the Promise. Catalyst: Feminism, Theory, Technoscience 1, 1 (Sept. 2015), 1-49. https://doi.org/10.28968/cftt.v1i1.28817 Number: 1.

[44] Rashida Richardson, Jason Schultz, and Kate Crawford. 2019. Dirty Data, Bad Predictions: How Civil Rights Violations Impact Police Data, Predictive Policing Systems, and Justice. SSRN Scholarly Paper ID 3333423. Social Science Research Network, Rochester, NY. https://papers.ssrn.com/abstract=3333423

[45] Devansh Saxena, Erhardt Graeff, Shion Guha, EunJeong Cheon, Pedro ReynoldsCuéllar, Dawn Walker, Christoph Becker, and Kenneth R Fleischmann. 2020. Collective Organizing and Social Responsibility at CSCW. In Conference Companion Publication of the 2020 on Computer Supported Cooperative Work and Social Computing. 503-509.

[46] Leigh Star and Geoffrey C. Bowker. 1999. Sorting Things Out: Classification and Its Consequences. MIT Press, Cambridge, MA.

[47] Lucy Suchman. 2000. Embodied Practices of Engineering Work. Mind, Culture, and Activity 7, 1-2 (May 2000), 4-18. https://doi.org/10.1080/10749039.2000.9677645 Publisher: Routledge_eprint: https://doi.org/10.1080/10749039.2000.9677645.

[48] John Vines, Rachel Clarke, Peter Wright, John McCarthy, and Patrick Olivier. 2013. Configuring Participation: On How We Involve People in Design. In Proceedings of the SIGCHI Conference on Human Factors in Computing Systems (Paris, France) (CHI '13). Association for Computing Machinery, New York, NY, USA, 429-438. https://doi.org/10.1145/2470654.2470716

[49] Tyreasa Washington, Theda Rose, Gia Colombo, Jun Sung Hong, and Stephanie Irby Coard. 2015. Family-level factors and African American children's behavioral health outcomes: A systematic review. In Child \& Youth Care Forum, Vol. 44. Springer, 819-834.

[50] Xuecong Xu, Xiang Yan, and Tawanna R. Dillahunt. 2019. Reaching Hard-ToReach Populations: An Analysis of Survey Recruitment Methods. In Conference Companion Publication of the 2019 on Computer Supported Cooperative Work and Social Computing. ACM, Austin TX USA, 428-432. https://doi.org/10.1145/ 3311957.3359447 